\title{
PEMISAHAN Zr - Hf SECARA SINAMBUNG MENGGUNAKAN MIXER SETTLER
}

\author{
Dwi Biyantoro', Isyuniarto', Masrukan ${ }^{2}$ \\ 1. Pusat Sains Teknologi Akselerator - BATAN \\ Jalan Babarsari Kotak Pos 6101 YKBB Yogyakarta 55281 \\ 2.Pusat Teknologi Bahan Bakar Nuklir, BATAN \\ Kawasan Puspiptek, Serpong, Tangerang Selatan, 15314 \\ e-mail : dwi.biyantoro@batan.go.id
}

(Naskah diterima : 26-06-2016, Naskah direvisi: 19-08-2016, Naskah disetujui: 29-08-2016)

\begin{abstract}
ABSTRAK
PEMISAHAN Zr - Hf SECARA SINAMBUNG MENGGUNAKANMIXER SETTLER. Telah dilakukan pemisahan $\mathrm{Zr}$ - Hf secara sinambung menggunakan pengaduk pengenap (mixer settler) 16 stage. Larutan umpan adalah zirkon nitrat dengan kadar $\mathrm{Zr}=30786 \mathrm{ppm}$ dan $\mathrm{Hf}=499 \mathrm{ppm}$. Ekstraktan dipakai adalah solven $60 \%$ TBP dalam kerosen dan larutan scrubbingyang dipakai adalah asam nitrat $1 \mathrm{M}$. Umpan masuk pada stageke 5 dikontakkan secara berlawanan arah dengan solven masuk pada stage ke 16 dan larutan scrubbing masuk pada stage ke 1 . Tujuan penelitian ini adalah memisahkan unsur $\mathrm{Zr}$ dan $\mathrm{Hf}$ dari hasil olah pasir zirkon menggunakan solven TBP dengan alat mixer settler16 stage. Analisis umpan dan hasil proses pemisahan untuk zirkonium ( $\mathrm{Zr}$ ) dilakukan dengan menggunakan alat pendar sinar- $\mathrm{X}$, sedangkananalisis unsur hafnium (Hf) menggunakan Analisis Pengaktifan Neutron (APN). Parameter penelitian dilakukan dengan variasi keasaman asam nitrat dalam umpan dan variasi waktu pada berbagai laju pengadukan. Hasil penelitian pemisahan unsur $\mathrm{Zr}$ dengan $\mathrm{Hf}$ diperolehkondisi optimum pada keasaman umpan $4 \mathrm{~N} \mathrm{HNO}_{3}$, keseimbangan dicapai setelah 3jam dan laju pengadukan 3300 rpm. Hasil ekstrak unsur zirkon ( $\mathrm{Zr}$ ) diperoleh kadar sebesar 28577 ppm dengan efisiensi $92,76 \%$ serta kadar pengotor hafnium (Hf) sebesar $95 \mathrm{ppm}$.
\end{abstract}

Kata Kunci: pemisahan Zr, Hf, ekstraksi, mixer settler, alat pendar sinar-X, APN. 


\section{ABSTRACT}

SEPARATION of Zr - Hf CONTINUOUSLY USE THE MIXER SETTLER. Separation of Zr - Hf continuously using mixer settler 16 stage has been done. The feed solution is zircon nitrate concentration of $\mathrm{Zr}=30786 \mathrm{ppm}$ and $\mathrm{Hf}=499 \mathrm{ppm}$. As the solvent used extractant $60 \% \mathrm{TBP}$ in $40 \%$ kerosene. Nitric acid solution used srubbing $1 \mathrm{M}$. The feed entered into stage to 5 is contacted with solvents direction on the stage to 16 and the scrubbing solution enter the stage to 1. The purpose of this study is to separate $\mathrm{Zr}$ and $\mathrm{Hf}$ of the results from the process of zircon sand using solvent TBP using 16 stage mixer settler. Analysis of the feed and the results of the separation process for zirconium $(\mathrm{Zr})$ using $X$-ray fluorescence instrument which hafnium $(\mathrm{Hf})$ using Neutron Activation Analysis (AAN). Parameter study done of acidity variation of nitric acid in the feed and time variation in various stirring speed. From the research the separation of $\mathrm{Zr}-\mathrm{Hf}$, the optimum conditions in acidity feed $4 \mathrm{~N} \mathrm{HNO}_{3}$, equillibrium was received after 3 hours, and stirring speed of $3300 \mathrm{rpm}$ obtained extract of zircon (Zr) concentration $=28577 \mathrm{ppm}$ (effisiency of $\mathrm{Zr}=92,76 \%)$ with impurities of hafnium $(\mathrm{Hf})=95 \mathrm{ppm}$.

Keywords: separation of $\mathrm{Zr}, \mathrm{Hf}$, extraction, mixer settlers, $X$-ray fluorescence, NAA. 


\section{PENDAHULUAN}

Zirkonium (Zr) merupakan salah satu bahan penting dalam industri nuklir maupun non nuklir karena mempunyai sifat tahan korosi pada suhu tinggi dan memiliki sifat fisis yang baik, sehingga kegunaannya dalam industri modern sangat diperlukan ${ }^{[1,2]}$. Dalamreaktor nuklir zirkonium terutama digunakan sebagai kelongsong elemen bakar karena mempunyai tampang lintang serapan neutron termal yang rendah yaitu sebesar 0,185 barn $^{[1-6]}$.Zirkonium dalam bentuk zirconium carbide ( $\mathrm{ZrC})$ dapat digunakan sebagai pelapis partikel pengganti silicon carbide (SiC) pada elemen bahan bakar (TRISO) Reaktor Suhu Tinggi $(\mathrm{RST})^{[6-9]}$.

Pulau Bangka di Indonesia adalah salah satu daerah yang mempunyai sumber daya mineral pasir zirkon $\left(\mathrm{ZrSiO}_{4}\right)$ dengan kadar $\mathrm{Zr}$ sekitar $40 \%$ dengan pengotor antara lain: $(\mathrm{Hf}=1,39 \%, \mathrm{Si}=20,75 \%$ dan $\mathrm{Sn}=1,27 \%)^{(4)}$. Agar zirkonium dapat digunakan sebagai bahan dalam reaktor nuklir, disyaratkan untuk bersih dari pengotornya terutama dari unsur hafnium $(\mathrm{Hf})$. Hafnium mempunyai penampang lintang serapan netron yang tinggi yaitu 102 barn, dan dapat digunakan sebagai batang kendali $^{(1,2,5,8)}$. Persyaratan penggunaan $\mathrm{Zr}$ dalam reaktor nuklir harus mempunyai kemurnian yang tinggi dengan kadar maksimal unsur pengotor $\mathrm{Hf}$ sebesar 100 $\mathrm{ppm}^{[1,2,3,6,8,8]}$.

Zirkonium dan hafnium mempunyai sifat kimia yang sangat mirip sehingga untuk pemisahannya diperlukan cara pemisahan kimia antara lain dengan proses ekstraksi dan penukar ion ${ }^{[1,2,3,4,5,6]}$. Kemiripan dan perbedaan keduanya terletak pada jari-jari ionzirkonium sebesar $0,74^{\circ} \mathrm{A}$ dan hafnium sebesar $0,75{ }^{\circ} \mathrm{A}$. Densitas $\mathrm{Zr}=6,49 \mathrm{~g} / \mathrm{cm}^{3}$ dan $\mathrm{Hf}=13,31 \mathrm{~g} / \mathrm{cm}^{3}$, nomor atom $\mathrm{Zr}=40$ dan $\mathrm{Hf}=91,2$. Beberapa metode yang telah dilakukan untuk pemisahan unsur $\mathrm{Zr}$ dengan $\mathrm{Hf}$ adalah proses fraksinasi kristalisasi ${ }^{[4,6]}$, pertukaran ion ${ }^{[2,3,4,8,9,10]}$, fraksinasi distilasi ${ }^{[2]}$, termal difusi ${ }^{[2]}$, ekstraksi pelarut ${ }^{[1,3,4,5,6,11,14-}$ ${ }^{19]}$ dan proses elektro kimia ${ }^{[2]}$. Laddha (1976) menyatakan bahwa proses ekstraksi lebih ekonomis digunakan untuk pemisahan campuran bahan dengan sifat kimia yang miripantara satu dengan yang lain dibandingkan dengan proses distilasi ${ }^{[12]}$.

Metode ekstraksi cair-cair didasarkan pada perbedaan koefisien distribusi zat terlarut dalam dua larutan yang tidak saling bercampur. Atas dasar pertimbangan kemudahan dan laju proses, kemur-nian produk yang tinggi, efektif dan selektivitas yang tinggi, maka metoda ini semakin bersaing dengan metode pemi-sahan lainnya. Solven yang digunakan untuk ekstraksi pada pemisahan zirkonium dan hafnium yaitu tributil fosfat $(\mathrm{TBP})^{[1,3,4,5,6,}$ 9,11,14,16,21] , metil isibutil keton (MIBK) ${ }^{[3,5,6]}$, D2EHPA ${ }^{[6,18]}$, cyanex ${ }^{[18]}$, Aliquat $336^{[3]}$ dengan pengencer kerosene, $\mathrm{n}$ heptan, dodekan, xylen dan eter ${ }^{[4,6,11]}$.

Proses pemisahan pada umumnya memerlukan kontak antar fasa yang baik, yang bisa dicapai dengan membuat gerak aliran dengan turbulensi tinggi agar laju perpindahan cukup tinggi tetapi pressure dropyang memadai melalui pemakaian kolom pulsa, dan penambahan penghalang. Pada permulaan pemisahan unsur $\mathrm{Zr}$ dan $\mathrm{Hf}$ menggunakan proses ekstraksi menggunakan dua solven yang berbeda yaitu menggunakan solven metil iso butil keton (MIBK) - tio sianat dengan larutan asam klorida danmenggunakan tri butil fosfat (TBP) dalam suasana asam nitrat. Proses ekstraksi mnggunakan solven MIBK digunakan untuk mengekstrak unsur $\mathrm{Hf}$ sedangkan solven TBP lebih sesuai untuk mengambil unsur $\mathrm{Zr}^{[3]}$.

Takahashi, dkk. (1993) menyusun sebuah kolom ekstraksi mixer-settler dengan mixer dan settler disusun secara vertikal pada tiap-tiap stage, dan telah membuktikan bahwa throughput maupun efisiensi meningkat dengan peningkatan laju penga- 
dukan ${ }^{[20]}$. Ekstraksi dapat dilakukan secara batch maupun kontinyu, satu tingkat maupun multi tingkat. Ekstraksi multi tingkat (mixer settler) dengan aliran berlawanan arah dapat digunakan secara efektif pada kapasitas besar untuk pemisahan logam bila dilakukan pengadukan yang cukup kuat ${ }^{[21]}$. Secara umum, mixer settler merupakan suatu alat ekstraksi yang mempunyai kelebihan bila dibanding alat lain, yaitu sirkulasi aliran massa kedua fase (fase berat dan fase ringan) dapat diatur sehingga tidak terjadi arus pintas dan back mixing. Disamping itu mixer settler dapat menghasilkan produk dengan kemurnian tinggi dari campuran logam yang mem-punyai sifat yang mirip ${ }^{[5,16,20]}$. Christina, dkk. (2013) melakukan pemisahan unsur $\mathrm{Zr}$ dan $\mathrm{Hf}$ dari larutan nitrat mnggunakan proses ekstraksi menggunakan solvent TBP dan Cyanex 923. Proses ekstraksi tersebut memberikan efisiensi ekstraksi Zr sebesar 91,60\% dan efisiensi Hf sebesar $12,10 \%$ dengan faktor pemisahan $\mathrm{Zr} / \mathrm{Hf}$ sebesar $79,3^{[1]}$.

Mixer-settler pertama kali digunakan dalam industri nuklir karena alat tersebut tidak memerlukan ruangan yang luas, pengoperasian dan perawatanyang mudah. Biasanya, mixer settler terdiri dari bebera stage yang tidak memerlukan pemipaan dan prinsip kerjanya berdasarkan beda densitas untuk memberikan "driving force" untuk aliran fluida. Sejak itu, penggunaan mixersettler telah menyebar ke berbagai aplikasi dan banyak dimanfaatkan di industri pertambangan maupun industri metalurgi. Alat tersebut bisa digunakan baik dalam skala laboratorium maupun skala industri dan handal. Kelebihan yang lain adalah kaskadenya dapat disusun secara horisontal sehingga tidak memerlukan ruangan yang tinggi, serta memungkinkan penambahan stage setiap saat.

Teknologi pemisahan unsur $\mathrm{Zr}-\mathrm{Hf}$ menggunakan proses ekstraksi cair-cair terus dikembangkan karena mengarah padaa) pengembangan solven baru agar lebih selektif terhadap ion tertentu, b) pemakaian kembali solven ke dalam proses, sehingga dapat menghemat biaya, c) peningkatkan unjuk kerja proses agar kebutuhan energi lebih rendah, d) peralatan yang lebih kecil, e) kebutuhan bahan solven yang lebih hemat, dan f) menghasilkan limbah yang lebih sedikit. Metode ini terus dikembangkan untuk membuat proses ekstraksi lebih efisien dan efektif dalam meningkatkan produksi ${ }^{(4)}$.

Berdasarkan hasil kajian oleh Biyantoro dan Muhadi $(2010)^{[4]}$, penelitian ekstraksi pemisahan unsur $\mathrm{Zr}-\mathrm{Hf}$ dengan proses ekstraksi cair-cair dapat dilakukan menggu-nakan umpan zirkonium oksida klorida (ZOC) dengan solven tributil fosfat (TBP).

Tujuan penelitian ini adalah memisahkan unsur $\mathrm{Zr}$ dan $\mathrm{Hf}$ dari hasil olah pasir zirkon (ZOC) dengan proses ekstraksi memakai solven TBP-kerosen menggunakan alat mixer settler 16 stage.

Zirkonium oksida klorida yang digunakan sebagai umpan proses ekstraksi diperoleh dari hasil proses peleburan pasir zirkon dengan natrium hidroksida, pelindihan air, pelindihan asam klorida yang diteruskan dengan pemekatan. Keberhasilan proses pemisahan unsur zirkonium dan hafnium ditentukan oleh banyaknya zirkon yang terambil ke fasa organik (TBP) dan sedikit mungkin pengotor hafnium yang ikut masuk ke dalam fasa organik. Untuk itu dilakukan penelitian pemisahan unsur $\mathrm{Zr}-\mathrm{Hf}$ dengan proses eks-traksi secara sinambung menggunakan alat mixer settler 16 stage menggunakan solven TBP. Sifat penting solven TBP yang lain adalah mudah didapat, harga yang relatif murah, kemampuan tinggi untuk diambil kembali(recovery), kelarutan rendah, tidak beracun, viskositasnya rendah, dan densitas kedua fase berbeda untuk menghindari terbentuknya emulsi. 


\section{TEORI}

Proses ekstraksi adalah pemisahan unsur-unsur dalam campuran larutan homogen berdasarkan perbedaan distribusi unsur-unsur yang mempunyai sifat yang mirip dalam dua cairan yang tidak saling bercampur ${ }^{(5,9)}$.Pada ekstraksi cair-cair, satu atau lebih komponen dari suatu campuran homogen dipisahkan menggunakan pelarut cair (solven) berdasarkan prinsip perbedaan kelarutan ${ }^{[4]}$.

Menurut hukum distribusi Nernst, bila ke dalam dua pelarut yang tidak saling bercampur dimasukkan solute yang dapat larut dalam kedua pelarut tersebut maka akan terjadi pembagian kelarutan. Dalam praktek solute akan terdistribusi dengan sendirinya ke dalam dua solven tersebut setelah diaduk dan dibiarkan terpisah. Perbandingan konsentrasi solute di dalam kedua solven tersebut tetap setelah mencapai keadaan setimbang, dan merupakan suatu tetapan pada temperatur tetap. Tetapan tersebut adalah tetapan distribusi atau sering disebut koefisien distribusi $(\mathrm{Kd})^{[6]}$.

Secara teknis pesawat pengaduk pengenap (mixer settler) adalah alat ekstraksi lawan arah yang digunakan untuk memisahkan zirkonium dan hafnium terdiri dari dua bagian yaitu bagian untuk proses ekstraksi terjadi dalam tangki berpengaduk dan bagian pemisahan terjadi dalam tangki pengenap.

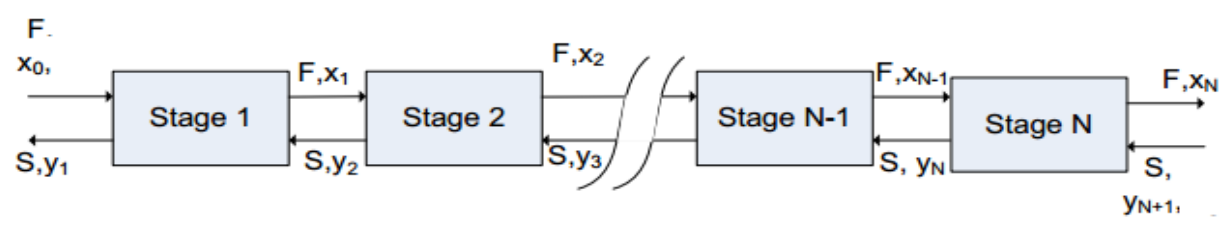

Gambar 1. Ekstraksi lawan arah dengan N stage

Apabila jumlah stage bertambah sebanyak $N$ seperti pada Gambar 1 maka dapat dibuat sebuah persamaan umum untuk setiap stage ke- $\mathrm{N}$ dan kesetimbangan pada setiap sebagai berikut ${ }^{[5]}$ :

Stage ke N :

$$
\begin{gathered}
\left(F \cdot x_{N-1}+S \cdot y_{N+1}\right)-\left(F \cdot x_{N}+S \cdot y_{N}\right)=0 \\
y_{N}=K d \cdot x_{N} \\
K d=y_{N} / x_{N}
\end{gathered}
$$

Pada keadaan setimbang, nilai koefi-sien distribusi $\mathrm{Zr}\left(\mathrm{Kd}_{\mathrm{Zr}}\right)$ dapat dihitung dengan cara perbandingan konsentrasi $\mathrm{Zr}$ dalam fasa organik (ekstrak) dibagi dengan konsentrasi $\mathrm{Zr}$ dalam fasa air (rafinat). Koefisien distribusi umumnya dinyatakan dengan rumus sebagai berikut ${ }^{[4,5,6,9,13,16)}$ :

$$
\mathrm{Kd}_{\mathrm{Zr}}=\frac{C_{E}}{C_{R}}
$$

$\mathrm{C}_{\mathrm{E}}$ adalah konsentrasi zirkonium ( $\mathrm{Zr}$ ) atau hafnium $(\mathrm{Hf})$ dalam fasa organik dan $C_{R}$ adalah konsentrasi $\mathrm{Zr}$ atau $\mathrm{Hf}$ dalam fasa air (rafinat).

Keberhasilan suatu proses ekstraksi diukur dengan besaran faktor pisah (FP) dan efisiensi ekstraksi. Faktor pisah merupakan perbandingan antara koefisien distribusi unsur $(\mathrm{Zr})$ dengan koefisien distribusi unsur $(\mathrm{Hf})$. Persamaan untuk memperoleh FP adalah $^{[4,5,6,9,13,16]}$ :

$$
\mathrm{FP}=\beta=\frac{K d_{Z r}}{K d_{H f}}
$$

$K d_{Z r}$ dan $K d_{H f}$ masing-masing adalah koefisien distribusi $\mathrm{Zr}$ dan koefisien distribusi Hf. Efisiensi ekstraksi adalahjumlah unsur yang terdistribusi ke dalam fasa organik (Co atau Fo) dibagi dengan unsur mula-mula dalam fasa umpan (Cu atau F), dapat ditulis 
dalam bentuk persamaan sebagai berikut $^{[4,5,6,9,13,16]}$ :

$$
\text { Efisiensi }(\%)=\frac{C o}{C u} \times 100 \%
$$

\section{METODOLOGI}

Bahan-bahan yang digunakan di dalam penelitianyaitu padatan zirkonium oksida klorida hasil olah pasir zirkon, TBP, kerosen, asam nitrat, amonia, dan air bebas mineral.
Rangkaian alat mixer settler yang digunakan dalam penelitian ditunjukkan pada Gambar 2. Satu unit alat mixer settler merk Sonal 16 stage, tiga buah pompa dosis, tiga buah tangki pengumpan, dua buah tangki penampung, voltage regulator, stop watch, gelas beker, gelas pemisah, magnetik stirrer, dan pipet. Alat yang digunakan adalah spektrometer pendar sinar-X dan analisis pengaktifan neutron (APN).

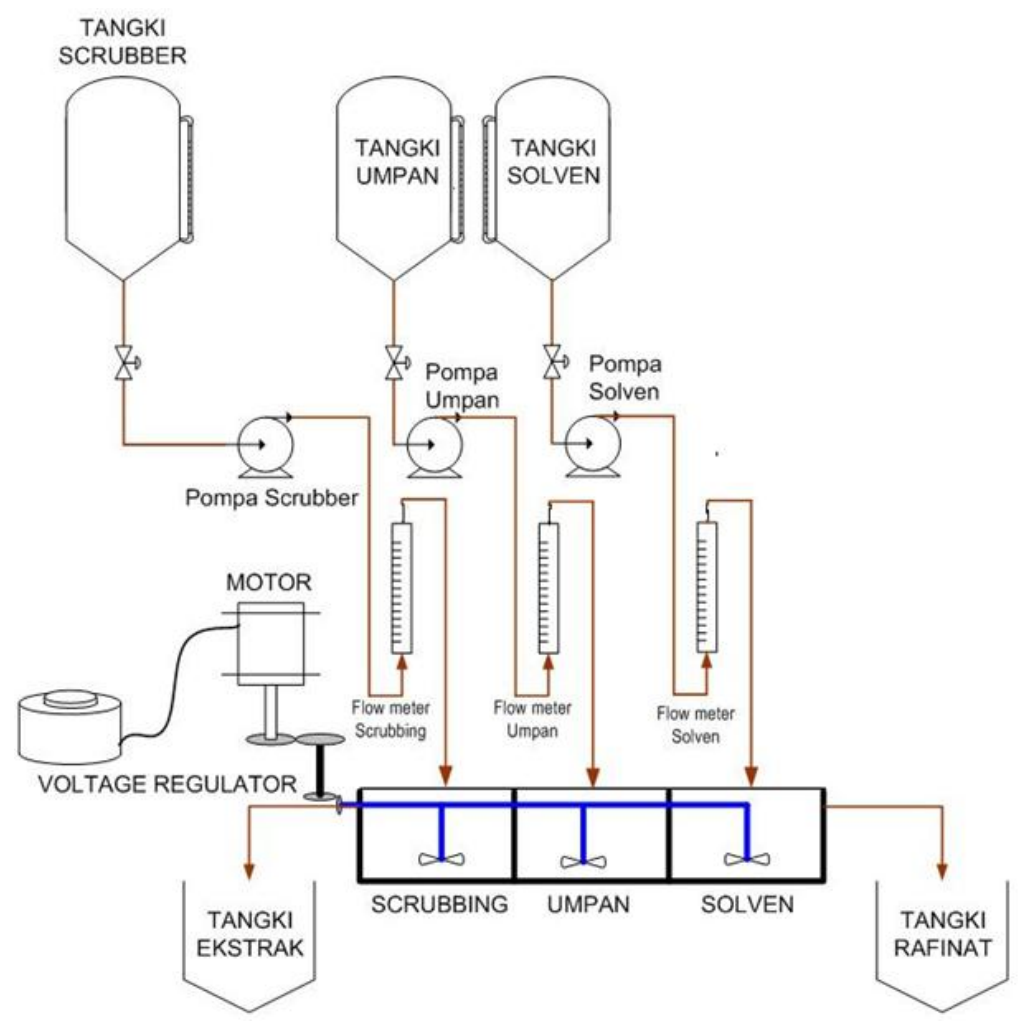

Gambar 2. Rangkaian alat mixer settler untuk pemisahan unsur $\mathrm{Zr}-\mathrm{Hf}$

Percobaan dilakukan dengan cara mencampur umpan dalam suasana nitrat pada keasaman sebesar $4 \mathrm{~N}$, pada berbagai waktu dan laju pengadukan. Pada setiap periode waktu setengah jam, filtrate yang dihasilkan selanjutnya dianalisis.

Dalam penelitian ini dipilih proses proses ekstraksi cair - cair menggunakan TBP - kerosen dengan umpan zirkonium oksida klorida (hasil olah proses zirkon) yang dilarutkan dalam asam nitrat direaksikan di dalam mixer settler secara kontinyu dengan aliran berlawanan arah.

Prosesawal yang dilakukan adalah melarutkan zirkon oksid klorid dalam berbagai variasi konsentrasi asam nitrat secara catu.Umpan zirkon nitrat $1 \mathrm{~N}$ sebanyak $10 \mathrm{~mL}$ kemudian ditambah dengan $40 \%$ TBP-kerosen sebanyak $20 \mathrm{~mL}$ diaduk dengan laju pengadukan $500 \mathrm{rpm}$ selama 30 menit. Campuran kemudian dipisahkan antara fasa air (rafinat) dan fasa organik dengan corong pisah. Percobaan di 
atas dilakukan pada berbagai keasaman umpanuntuk mencari kondisi optimum proses ekstraksi seperti ditunjukkan pada Gambar 1.

Penelitian diawali dengan catu proses ekstraksi larutan zirkon nitrat dengan meng-gunakan solven TBP-kerosen pada berbagai keasaman nitrat. Dari proses yang dilakukan diperoleh data hubungan antara konsentrasi larutan zirkon nitrat pada berbagai konsentrasi keasaman nitrat dan nilai konsentrasi asam nitrat optimum. Selanjutnya dibuat umpan larutan zirkon nitrat untuk proses ekstraksi cair-cair untuk memisahkan zirkonium $(\mathrm{Zr})$ dan hafnium $(\mathrm{Hf})$ pada keasaman nitrat yang optimum. Umpan larutan zirkon nitrat dibuat dengan cara melarutkan zirkonium oksida klorida dalam asam nitrat dengan konsentrasi tertentu dalam tangki umpan. Dibuat larutan asam nitrat $1 \mathrm{~N}$ untuk digunakan sebagai srubbing atau pencuci. Disiapkan juga larutan fasa organik tributil fosfat (TBP) dicampur dengan kerosen dengan perbandingan volum $=60 \%: 40 \%$ dalam tangki fasa organik. Larutan fasa organik di masukkan ke dalam stage 16, larutan umpan di masukkan pada stage ke 5, dan larutan scrubing pada stage ke 1.

Tahap permulaan dilakukan dengan mengisi ruangan pencampuran (mixer) dan ruangan pengenap settler dengan umpan zirkon nitrat dan fasa organik dalam perbandingan sebesar $1: 2$ sampai terisi setengahnya. Proses pengadukan kemudian dijalankan selama 5 - 10 menit. Setelah itu pompa-pompa, untuk solven (fasa organik) umpan dan scrubber dioperasikan secara berlawanan arah. Besarnya perbandingan laju alir fasa organik, fasa umpan, dan srubbing adalah $2: 1: 0,5$. Laju putar mixersettler dijaga agar interface pada posisisi tetap. Aliran kedua fasa yang telah melewati mixer settler ditampung dalam tangki ekstrak dan tangki rafinat. Masing-masing sampel fasa air (rafinat) kemudian dilakukan analisis kadar unsur $\mathrm{Zr}$ dengan menggunakan alat pendar sinar-X, sedangkan kadar $\mathrm{Hf}$ menggunakan analisis pengaktifan neutron.

\section{HASIL DAN PEMBAHASAN}

\section{a. Variasai keasaman asam nitrat}

Kadar unsur $\mathrm{Zr}$ dan $\mathrm{Hf}$ serta koefisien distribusi $(\mathrm{Kd}) \mathrm{Zr}$ dan $\mathrm{Hf}$ hasil proses ekstraksi pada berbagai keasaman asam nitrat ditunjukkankan pada Gambar 3 dan 4.

Asam nitrat selain berfungsi untuk reaksi pembentukan kompleks logam dengan TBP juga dapat berfungsi untuk melarutkan umpan. Semakin pekat $\mathrm{HNO}_{3}$, semakin mudah umpan terlarut. Konsentrasi $\mathrm{HNO}_{3}$ yang meningkat dapat meningkatkan reaktivitas pembentukan kompleks, tetapi pada keasaman yang terlalu tinggi akan menyebabkan solven TBP rusak karena menurunkan kemampuan mengikat $\mathrm{Zr}$, sehingga menurunkan distribusi $\mathrm{Zr}$ ke dalam fasa organik. Hasil percobaan menunjukkan bahwa kondisi umpan terbaik dalam suasana konsentrasi asam nitrat $4 \mathrm{~N}$. Parameter ini digunakan pada proses pemisahan $\mathrm{Zr}-\mathrm{Hf}$ dengan solven TBPkerosen menggunakan alat mixer settler 16 stage.

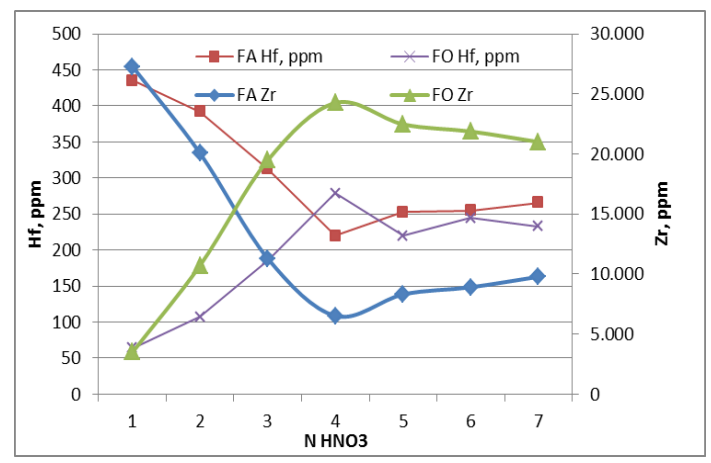

Gambar 3. Hubungan antara tingkat keasaman nitrat dengan kadar $\mathrm{Zr}$ dan $\mathrm{Hf}$

Hasil pada Gambar 3 di atas digunakan untuk menghitung $\mathrm{Kd}$ dan faktor pisah (FP) unsur $\mathrm{Zr}$ dengan $\mathrm{Hf}$. Hasil perhitungan $\mathrm{Kd}$ dan (FP) selengkapnya disajikan pada Gambar 4 dan 5. 


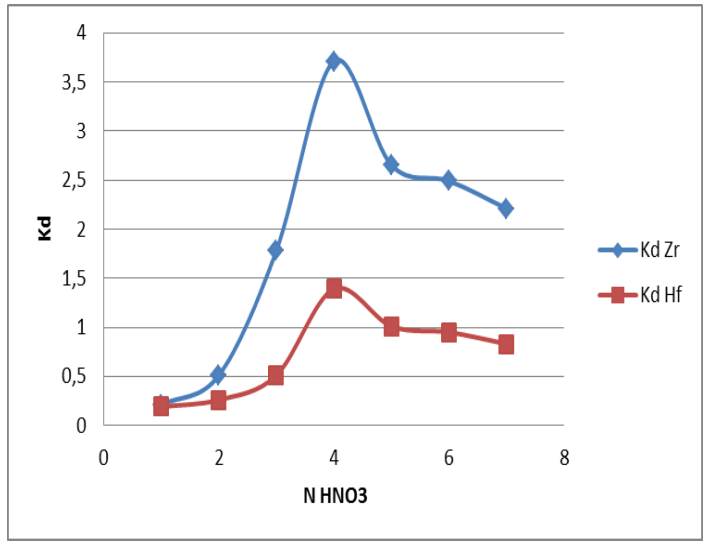

Gambar 4. Hubungan antara tingkat keasaman asam nitrat dengan $\mathrm{Kd}_{\mathrm{Zr}}$ dan $\mathrm{Kd}_{\mathrm{Hf}}$

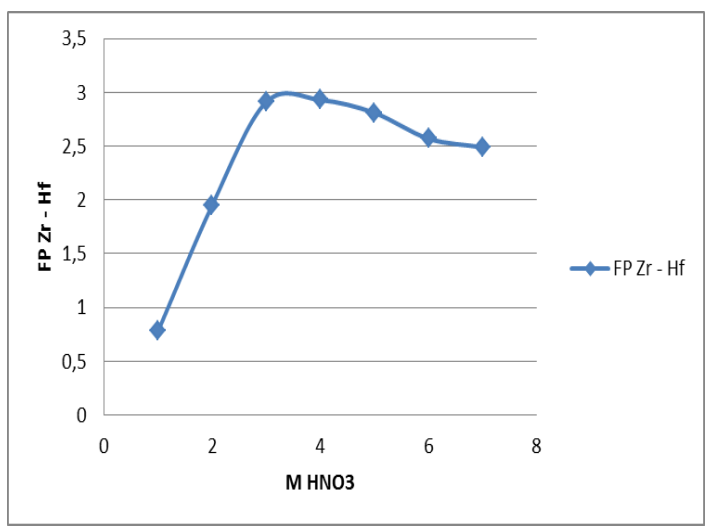

Gambar 5. Hubungan antara tingkat keasaman asam nitrat dengan $\mathrm{FP}_{\mathrm{Zr}-\mathrm{Hf}}$

Hasil perhitungan menggunakan data pada Gambar 3 diperoleh hubungan antara konsentrasi $\mathrm{HNO}_{3}$ dengan koefisien distribusi (Kd) $\mathrm{Zr}$ dan $\mathrm{Kd} \mathrm{Hf}$ disajikan pada Gambar 4. Data ini selanjutnya digunakan untuk menghitung faktor pisah unsur $\mathrm{Zr}-\mathrm{Hf}$ seperti disajikan pada Gambar 5. Pada Gambar 5 tampak bahwa kondisi optimum diperoleh pada konsentrasi asam nitrat $4 \mathrm{~N}$ dengan faktor pisah yang tertinggi sekitar 3 .

\section{b. Variasi waktu pada berbagai laju pengadukan}

Kadar $\mathrm{Zr}$ hasil proses ekstraksi dengan variasi waktu dan laju pengadukan disajikan pada Gambar 6.

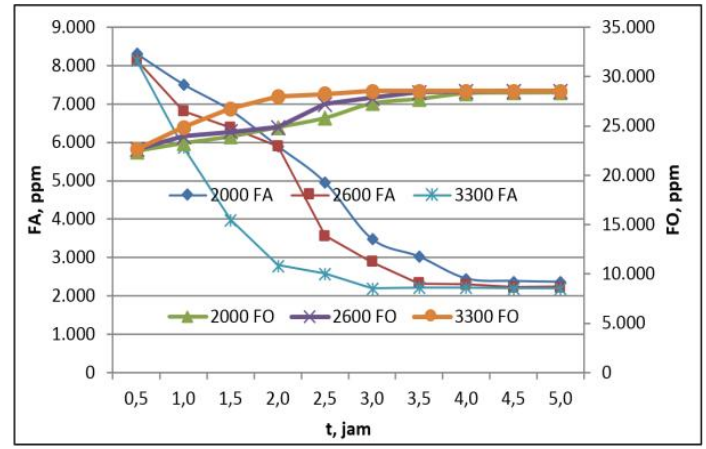

Gambar 6. Hubungan antara variasi waktu pada berbagai laju pengadukan terhadap kadar Zr.

Gambar 6 menunjukkan bahwa pada laju pengadukan sebesar $3300 \mathrm{rpm}$ keseimbangan mulai tercapai setelah operasi berjalan selama 3 jam. Setelah melewati 3,5 jam sudah tidak terjadi perubahan yang nyata. Hal ini menunjukkan bahwa perpindahan massa zirkonium ke dalam fasa organik relatif sudah tetap, sudah tidak terjadi perpindahan massa lagi, hal ini karena terjadi kontak antar fasa yang lebih sempurna. Waktu pengadukan ini sudah cukup optimal untuk terjadinya reaksi dan terbentuknya hasil reaksi, sehingga diperoleh efisiensi yang optimal.

Pada laju pengadukan sebesar 2600 rpm dan 2000 rpm waktu untuk mencapai kesimbangan sedikit lebih lama yaitu di atas 3,5 jam. Profil distribusi zirkonium ke dalam fasa organik TBP cenderung hampir sama dengan perbedaanpada waktu mencapai keseimbangan. Laju pengadukan yang lebih tinggi mengakibatkan waktu penca-paian keseimbangan akan lebih singkat.

Laju pengadukan campuran fasa air dan fasa organik mempengaruhi hasil distribusi unsur-unsur yang ada dalam umpan menuju ke fasa ekstraktan sebelum keseimbangan dicapai. Dengan laju pengadukan yang semakin besar maka lapisan difusi semakin tipis. Ketebalan lapisan difusi merupakan ukuran hambatan terjadinya laju perpindahan massa sebelum tercapai kesetimbangan. Dengan meningkatnya laju 
pengadukan,maka intensitas terjadinya tumbukkan antara reaktan semakin banyak dan semakin cepat ${ }^{[6]}$.

Waktu kontak antara umpan (fasa air) dengan fasa organik (TBP-kerosen) akan mempengaruhi distribusi solute ke dalam fasa organik. Semakin lama waktu kontak antara fasa air dengan fasa organik selama proses ekstraksi maka semakin banyak pula jumlah unsur $\mathrm{Zr}$ yang terikat oleh TBP. Setelah tercapai keadaan setimbang, jumlah unsur yang terekstrak ke fasa organik tidak lagi dipengaruhi oleh waktu pengadukan.

Gambar 6 menunjukkan bahwa dengan laju pengadukan semakin tinggi, zirkon yang terambil semakin besar. Hal ini disebabkan karena pengadukan semakin tinggi akan membuat ukuran butir yang terlarut menjadi semakin kecil sehingga luas bidang kontak juga semakin besar, dan menyebabkan kenaikkan jumlah zirkon ke fasa organik meningkat ${ }^{[6]}$. Kadar $\mathrm{Zr}$ pada fasa rafinat keluaran settler makin berkurang dengan meningkatnya laju putaran pengadukan, dengan demikian turbulensi di dalam mixer menjadi lebih baik. Meningkatnya turbulensi di dalam mixer, menyebabkan luas bidang kontak persatuan volum antara fasa kontinyu dan fasa dispersi meningkat.

Berdasarkan data yang disajikan pada Gambar 6 dan hasil analisis rafinat pada variasi laju pengadukan diperoleh kadar $\mathrm{Hf}$ dalam ekstrak seperti disajikan pada Tabel 1.

Tabel 1. Kadar Hf dalam ekstrak hasil ekstraksi

\begin{tabular}{|c|c|c|}
\hline No. & $\begin{array}{c}\text { Laju } \\
\text { pengadukan, } \\
\text { rpm }\end{array}$ & $\begin{array}{c}\text { Kadar Hf dalam } \\
\text { FO, } \\
\text { ppm }\end{array}$ \\
\hline 1 & 2000 & 123 \\
\hline 2 & 2600 & 97 \\
\hline 3 & 3300 & 95 \\
\hline
\end{tabular}

Gambar 6 dan Tabel 1 menunjukkan bahwa proses pemisahan $\mathrm{Zr}-\mathrm{Hf}$ dengan kadar umpan unsur sebesar $\mathrm{Zr}=30786 \mathrm{ppm}$ dan kadar $\mathrm{Hf}=499$ ppmdalam suasana asam nitrat $4 \mathrm{~N}$ menggunakan60\% TBP $40 \%$ kerosin dengan alat mixer settler 16 stage pada laju pengadukan $3300 \mathrm{rpm}$ diperoleh ekstrak Zr dengan kadar 28577 ppm (efisiensi sebesar $=92,76 \%$ ) dan kadar unsurpengotor $\mathrm{Hf}$ diperoleh sebesar $=$ $95 \mathrm{ppm}$. Hasil penelitian ini menunjukkan bahwa efisiensi $\mathrm{Zr}$ yang diperoleh lebih besar dari pada hasil studi yang dilakukan oleh Christina, dkk. (2013) pada pemisahan zirkonium dan hafnium dalam larutan asam nirat dengan ekstraksi solven diperoleh efisiensi $\mathrm{Zr}=91,60 \%{ }^{(1)}$.

\section{SIMPULAN}

Pemisahan unsur $\mathrm{Zr}$ - $\mathrm{Hf}$ secara sinambung menggunakan mixer settler merk Sonal 16 stagedengan perbandingan laju alir fasa organik, fasa umpan, dan srubbing yaitu $2: 1: 0,5$ dapat disimpulkan bahwa larutan umpan dalam suasana asam nitrat $4 \mathrm{~N}$ diperolehwaktu keseimbangan setelah operasi 3 jam pada laju penga-dukan 3300 rpm. Hasil pemisahan unsur antara $\mathrm{Zr}$ dan $\mathrm{Hf}$ menggunakan kadar umpan $\mathrm{Zr}$ sebesar 30786 ppm dan Hf 499 ppm suasana asam nitrat $4 \mathrm{~N}$ diperoleh hasil ekstrak $\mathrm{Zr}$ dengan kadar 28577 ppm (efisiensi $Z r=92,76 \%$ ) dengan kadar pengotor hafnium sebesar $95 \mathrm{ppm}$.

\section{UCAPAN TERIMAKASIH}

Penulis mengucapkan banyak terima kasih kepada Ka.PSTA - BATAN Yogyakarta yang telah memberikan dana DIPA untuk penelitian dan juga kepada Sdri.Tri Handini, Sdr. R. Subagiono, Purwoto, Sudarso, Sukiman, R. Sudibyo, Mulyono, dan Rochyanto yang telah membantu selama percobaan dan pengoperasian Mixer Settler. 


\section{DAFTAR PUSTAKA}

[1] Cristina, J., Amaral, Laura,(2013), "Study of the Separation of Zirconium and Hafnium From Nitric Solutions by Solvent Extraction", International Nuclear Atlantic Conference - INAC, Brazil, 24-29.

[2] Felipel, E. C. B., Phalharel, H. G., Ladeira, (2013), "Separation of Zirconium From Hafnium by Ion Exchange", International Nuclear Atlantic Conference - INAC, Brazil, 24-29.

[3] Westhuizen, D.J.,(2010), "Separation of Zirconium and Hafnium via Solvent Extraction", Dessertation, Petchefstroom Campus of the Norst-West University.

[4] Biyantoro, D. Dan Muhadi, (2010), "Kajian Pemisahan $\mathrm{Zr}$ - Hf Dengan Proses Ekstraksi Cair-Cair", Prosiding Pertemuan dan Presentasi IImiah IPTEK Nuklir, PTAPB-BATAN, Yogyakarta.

[5] Sahira, K. V., (2013), "Matrix Studies on Solvent Extraction of Zirconium and Hafnium from Loaded Solvent obtained from Scrub Raffinate", International Journal of Engineering Science Invention, Volume 2, pp. 123146, India.

[6] Biyantoro, D., Purwani, M. V., (2013), "Optimasi Pemisahan $\mathrm{Zr}$ - Hf Dengan Cara Ekstraksi Memakai Solven Topo", J. Tek. Bhn. Nukl. , Vol/ 9. No. 1, 1-54.

[7] Zhou, X. W. And Tang, C. H., (2010), Current Status and Future Development of Coated Fuel Particles for High Temperature Gas-Cooled Reactor, Progress in Nuclear Energy, XXX. 1-7.

[8] Gde Pandhe, W.S., (2012), "Migrasi Zirkonium dan Hafnium Pada
Tumpukan Resin Anion Dalam Rangka Simulasi Pemisahannya Dengan Kromatografi Anular", Tesis, Program Pasca Sarjana UGM, Yogyakarta.

[9] Yang, X. J., Pin, C., And Fane, A., G., (1999), "Separation of Hafnium from Zirconium by Extraction Chromatography with Liquid Anionic Exchangers", Journal of Chromatographic Science, Vol. 17.

[10] Susiantini, E., Setyadji, M., (2012), "Pemisahan Zr-Hf Dalam Asam Sulfat Dengan Resin Penukar Anion", J. Tek. Bhn. Nukl., 67-78.

[11] Basuki, K. T., Biyantoro, (2011), "Kinetika Reaksi Pemisahan Zr-Hf Pada Ekstraksi Cair-Cair Dalam Media Asam Nitrat, Jurnal Teknologi Bahan Nuklir, Vol. 7 No. 1.

[12] Laddha, G. S. And Degallesan, T. E.,(1976), "Transport Phenomena in Liquid Extraction", Tata Mc.Graw-Hill Publishing Co., Ltd., New Delhi.

[13] Poriel, L., Reguillon, A. F., Rostaing, S., P., and Lemaire, M., (2006), "Zirconium and Hafnium, Part 1. Liquid/Liquid Extraction in Hydrochloric Acid Aqueous Solution with Aliquat 336", Research Gate, Separation Science and Technology, 41: 1927-1940.

[14] Sadigzadeh, A, Chehrenama, S., Shokri, H.,(2009), Solvent Extraction of Zirconium from Nitric - Hydrochloric Acid Solution Using TBP, Journal of Theoretical and Applied Phyics, Tehetan.

[15] Banda, R., Lee, H. Y., And Lee, M. S., (2012), Separation of Zr from Hf in Hydrochloric Acid Solution Using Amine-Based Extractants, Republic of Korea , Ind. Eng. Chem.Res, pp. 9652-9660. 
[16] Gharehbagh, F. S., Ali Mousavian, S. M., (2009), Hydrodynamic Characterization of Mixer Settlers, Journal of the Taiwan Institute of Chemical Engineer 40 302-312.

[17] Noronha, L. E., Kamble, G. S., Kolekar, S. S., Anuse, M. A.,(2013), "Solvent Extraction Separation of Zirconium (IV) with 2-Octylaminopyridine from Succinate MediaAnalysis of Real Samples", Indian Journal of Chemical Technology, Vol. 20, pp. 252-258.

[18] Wang, L, Lee, H., And Lee, M., (2015), "Solvent Extraction Separation of $\mathrm{Zr}$ and $\mathrm{Hf}$ from Nitric Acid Solutions by PC $88 \mathrm{~A}$ and Its Mixture with Other Extractans", Metal and Materials International, Volume 21, pp 166-172.
[19] Rezaee, M., Yamini, Y., Khanci, A., (2012), "Extraction and Separation of Zirconium from Hafnium Using a New Solvent Microextraction technique", Journal of the Iranian, Chemical Society, Volume 9, pp 67-74.

[20] Takahashi, K. S., Nakhashima, H., Nii, S., And Ttakeuchi, H., (1993), Maximum Thruoghput in Multistage MixerSettler Extract in Multistage MixerSettler Extraction Column, Kogaku Kogaku Ronbunshu.

[21] Mulyono, P., Bendiyasa, I. M., Sarto, (2004), Simulasi Unjuk Kerja MixerSettler Pada Ekstraksi Logam Berat dalam Limbah Cair Dengan Tri Buthyl Phosphate, Jurnal Teknik Kimia Indonesia, Vol. 3 No. 1, 9-17. 
